\title{
Effect of different dispersing additives on the morphology and the properties of polyethylene-based nanocomposite films
}

\author{
N. Tz. Dintcheva ${ }^{1 *}$, F. P. La Mantia ${ }^{1}$, V. Malatesta ${ }^{2}$ \\ ${ }^{1}$ Dipartimento di Ingegneria Industriale, Università di Palermo, Viale delle Scienze, ed.6, 90128 Palermo, Italy \\ ${ }^{2}$ Materials Science Department, Università Milano Bicocca, Via R. Cozzi 53, 20125 Milano, Italy
}

Received 10 February 2011; accepted in revised form 3 May 2011

\begin{abstract}
In this work, the use of a polar wax, e.g. amphiphilic Tegomer ${ }^{\circledR}$ E 525 (TEG) is investigated with the aim of modifying, and possibly improving, the dispersion of an organically modified nanoclay (OMMT), loaded at $5 \mathrm{wt} \%$, in a polyethylene matrix (PE) at relatively low loading levels. We have indeed found that the incorporation of low loadings, e.g. $0.5 \mathrm{wt} \%$, of TEG, an amphiphilic block co-polymer, into a PE/OMMT sample results in a substantial improvement of the clay dispersion in the nanocomposite and, consequently, of the mechanical and thermomechanical properties of the films. The achieved results are comparable to those obtained for systems containing traditional dispersing agents such as maleated PE (PEgMA) and ethylene-acrylic acid copolymer (EAA), at higher loadings, i.e. at $5 \mathrm{wt} \%$. It has also been found that by increasing the polar wax content, i.e. $1-5 \mathrm{wt} \%$, no useful improvement in the mechanical behaviour and morphology of the PE films was obtained. At high loadings of the polar wax relatively the short chains are arranged into the clay particles galleries and intercalation of the polyethylene chains between the clay platelets may be hindered. Additionally at high TEG loadings, the presence of the new polar groups of the wax also on external surfaces of the clay particles is expected to promote aggregation of the clay particles, with a loss of the beneficial effect of the more dispersed clay particles on the polymer mechanical/thermomechanical properties. The reported results strongly indicate that the amphiphilic TEG dispersing additive, may advantageously be used, at substantially lower loadings, as an alternative to incumbent PEgMA in the formulation of nanocomposites to improve their macroscopic performances.
\end{abstract}

Keywords: mechanical properties, dispersing additives, polyethylene-based nanocomposite, polar wax, film formulation

\section{Introduction}

It has been reported that thermoplastics filled with nanometer-sized materials show properties different from those of thermoplastics filled with conventional microsized particles. The incorporation of nanosized fillers has, indeed, been shown to have significant effects not only on some mechanical and thermomechanical properties e.g. elastic modulus, heat deflection temperature, but also on the transparency and haze characteristics of the polymers films. It is well documented that nanoclay incorporation into polymer films significantly enhances transparency, reduces haze and sizeably increases the film barrier properties. Clays, being hydrophilic, are easier to be nano-disperded in polar polymers. On the other hand preparation of clay-based nanocomposites by melt processing of polyolefins (PO's), thermoplastic olefins (TPO's) and other non-polar polymers is a technologically challenging task as the clay silicate layers have to be exfoliated by pure mechanical shear during the extrusion of the polymer. Extrusion conditions, extruder screw type and design strongly affect the exfoliation extent. In order to improve exfoliation, use of the more polar

\footnotetext{
${ }^{*}$ Corresponding author, e-mail: dintcheva@unipa.it
}

(C) BME-PT 
maleic anhydride-modified (maleated) POs, TPOs and organically modified clays may be required. The success of these materials requires also that the incorporation of the organically modified clay has negligible adverse effects on preparation, cost, processing stability and a host of other application specific performance properties.

When well dispersed low loadings $(1-10 \mathrm{wt} \%)$ of nanoclays yield dramatic improvement of physical, thermal, and mechanical properties of polymerbased materials with a minimal increase in the polymer density as a result of the low inorganic loading [1-10].

It must be noted that the improvement of all these properties occurs only if the nanofiller particles are exfoliated, or at least intercalated, within the polymer matrix. Intercalation or exfoliation is the result of the incorporation of polymer macromolecules between the layers of the exfoliated clay particles and occurs only if the extrusion-induced thermomechanical stress is well transferred from the melt to the layered particles. A good adhesion between matrix and particles is then a necessary condition for a successful intercalation or exfoliation. When polymer melt and filler are not well adherent, e.g. in the case of a non-polar matrix such as polyolefins containing polar particles such as nanoclays, use of an adhesion promoter or compatibilizer, having polar groups is necessary [11-25].

In order to modify the clay morphology and consequently the final macroscopic properties in clay filled polyethylene, different commercial compatibilizers have been used. Sánchez-Valdes et al. [11] have used Zn-neutralized carboxylate ionomer, while, Shah et al. [12] used Na-neutralized poly(ethylene co-methacrylic acid), both Surlyn ${ }^{\circledR}$ by DuPont, in LDPE/clay nanocomposite formulation. Filippi and coworkers [13-14] have used as a compatibilizer, the ethylene-acrylic acids copolymers (Et-gAA), namely Escor ${ }^{\circledR}$ by Exxon-Mobil. Xu et al. [15] have prepared HDPE/clay nanocomposites using a HDPE-g-AA co-polymer. The most widely used compatibilizer in polyethylene/clay formulations has been the maleic anhydride grafted polyethylene that allows obtaining an exfoliated clay morphology [16-23]. All the authors agree that the observed macroscopic benefits have been lower than those expected and calculated, for nanofilled polymer based systems, using different theoretical models.

Recently, a new type of polar compatibilizers, based on the oxidized polyolefin has been used in the polyethylene/silicate nanacomposite formulations. Durmuş et al. [24] concluded that the barrier and mechanical properties of the nanocomposites prepared with commercial grade oxidized polyethylene were better than those prepared with maleic anhydride grafted polyethylene. Furthermore, Luyt and Geethamma [25] have reported that the presence of oxidized paraffin slightly reduces the thermal stability of the LLDPE/clay sample.

In this work the use of a polar wax, e.g. amphiphilic Tegomer ${ }^{\circledR}$ E525 is investigated for the first time, with the aim of modifying, and possibly improving, the dispersion of an organically modified nanoclay (OMMT) in a PE matrix at relatively low loading levels. Interestingly the properties of the $0.5 \mathrm{wt} \%$ TEG containing PE/OMMT film are comparable to those of a PE/OMMT film containing a tenfold higher amount, i.e. $5 \mathrm{wt} \%$, of the traditionally used maleic anhydride grafted polyethylene (PEgMA). These new results strongly indicate that the amphiphilic TEG dispersing additive may be advantageously used, at relatively low loading levels, as an alternative to PEgMA.

\section{Experimental}

\subsection{Materials}

The materials used in this work were:

- LLDPE, PE, (Clearflex FG166, $M_{\mathrm{w}}=$ $130000 \mathrm{~g} \cdot \mathrm{mol}^{-1}, \quad M_{\mathrm{w}} / M_{\mathrm{n}}=3.8 ; \quad \mathrm{MFI}_{190 / 2.16}=$ $0.27 \mathrm{~g} / 10 \mathrm{~min}$ and $\rho=0.918 \mathrm{~g} \cdot \mathrm{cm}^{-3}$ at room temperature, Polimeri Europa, Rome, Italy);

- an organomodified clay, OMMT, (Cloisite ${ }^{\circledR} 15 \mathrm{~A}$ from Southern Clay Products, Gonzales, TX, USA) was used to prepare the hybrid blend. Cloisite ${ }^{\circledR} 15 \mathrm{~A}$ is a montmorillonite modified by dimethyl-dihydrogenated tallow-quaternary ammonium cation with a concentration of the organo-modified clay of $125 \mathrm{meq} / 100 \mathrm{~g}$ and density $\rho=1.66 \mathrm{~g} / \mathrm{cm}^{3}$. The OMMT was added at $5 \mathrm{wt} \%$ in all formulations; - a maleic anhydride grafted polyethylene, PEgMA, with $\mathrm{MFI}_{190^{\circ} \mathrm{C} / 2.16 \mathrm{~kg}}=5 \mathrm{~g} / 10 \mathrm{~min}\left(\right.$ Polybond $^{\circledR} 3009$, from Crompton Corp., Middelbury CT, USA). The maleic anhydride level is $1 \mathrm{wt} \%$, reported from the manufacturer. The PEgMA was added at $5 \mathrm{wt} \%$; 
Table 1. Sample composition and ration between dispersing additives and OMMT

\begin{tabular}{|l|c|c|}
\hline \multicolumn{1}{|c|}{ Sample code } & $\begin{array}{c}\text { Composition } \\
\text { wt/wt/wt\% }\end{array}$ & $\begin{array}{c}\text { Ratio between } \\
\text { dispersing additive and } \\
\text { OMMT }\end{array}$ \\
\hline PE/OMMT & $95 / 5$ & - \\
\hline PE/PEgMA/OMMT & $90 / 5 / 5$ & 1.0 \\
\hline PE/EAA/OMMT & $90 / 5 / 5$ & 1.0 \\
\hline $\mathrm{PE} / \mathrm{TEG} 0.5 / \mathrm{OMMT}$ & $94.5 / 0.5 / 5$ & 0.1 \\
\hline $\mathrm{PE} / \mathrm{TEG} / \mathrm{OMMT}$ & $94 / 1 / 5$ & 0.2 \\
\hline $\mathrm{PE} / \mathrm{TEG} / \mathrm{OMMT}$ & $91 / 4 / 5$ & 0.8 \\
\hline $\mathrm{PE} / \mathrm{TEG}$ /OMMT & $90 / 5 / 5$ & 1.0 \\
\hline
\end{tabular}

- an ethylene-acrylic acid copolymer, EAA, $\left(\right.$ Escor $^{\circledR}$ 5001 from Exxon-Mobil Chemical Mediterranea, Milan, Italy) was used to prepare a compatibilized blend. The composite film has an acrylic acid con-

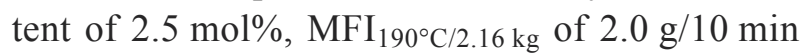
and $\rho=0.931 \mathrm{~g} / \mathrm{cm}^{3}$. The EAA was added at $5 \mathrm{wt} \%$; - alternatively a polar wax e.g. Tegomer ${ }^{\circledR}$ E 525, TEG, (Evonik Goldschmidt Italia, s.r.l., Pandiono, Italy), added at different $w t \%$, i.e. 0.5, 1.0, 2.0, 4.0 and 5.0 was used to achieve a better dispersion of the nanoclay. TEG is a finely grained white powder with a melting point close to $100^{\circ} \mathrm{C}$ and a melt viscosity of $200 \mathrm{mPa} \cdot \mathrm{s}$ at $140^{\circ} \mathrm{C}$.

The composition of all nanocomposite films and ratio between the dispersing additives and OMMT were reported in Table 1.

\subsection{Processing}

The nanocomposite films were prepared considering two consecutive separate processing. In particular, first step was the compounding in twin screw extruder, in order to have a better additive dispersion and second step was the film formulation using a film-blowing apparatus.

\section{First processing step: Compounding}

The PE was melt-compounded with nanofiller and different dispersing additives (different type and loading) in a co-rotating inter-meshing twin-screw extruder $(L / D=35, D=19 \mathrm{~mm}, \mathrm{OMC}$, Saronno,
Italy), using a shear stress screw profile as reported in Figure 1. The temperature profile used was 120 120-160-170-180-180 ${ }^{\circ} \mathrm{C}$ (die) and the residence time was about $120 \mathrm{~s}$ at $250 \mathrm{rpm}$. The extrudates were water-cooled, and granulated before the film formulation.

\section{Second processing step: Film formulation}

The films were prepared with a single-screw extruder equipped with a film blowing head and with a Brabender film-blowing unit (Braneder Technologie KG, Duisburg, Germany). The thermal profile was $120-140-170-190^{\circ} \mathrm{C}$ and the screw speed $60 \mathrm{rpm}$. The obtained film thickness was about 80 microns.

\subsection{Characterizations}

\subsubsection{Mechanical test}

The tensile properties were determined at room temperature and humidity, by using an Instron machine mod. 3365 (Instron, Norwood, MA, USA), according to ASTM test method D882. The specimens were cut from films in both the machine and transverse direction (machine, MD, and transverse, TD), and were tested at two strain rates: for modulus measurement purposes, the speed was $1 \mathrm{~mm} / \mathrm{min}$ until a deformation of $10 \%$, and that was subsequently increased to $500 \mathrm{~mm} / \mathrm{min}$ until break. The data reported are the average values of ten tests per film sample, the reproducibility being $\pm 5 \%$.

\subsubsection{Scanning electron microscopy (SEM)}

SEM analysis was performed on the nitrogen fractured surfaces of all the films on a Philips (Netherlands, distributed by FEI, Hillsboro, Oregon USA) ESEM XL30 microscope.

\subsubsection{X-ray analyses (X-ray)}

Wide-angle X-ray analyses (WAXD) were performed at room temperature in the reflection mode on a Siemens D-500 X-ray diffractometer (Siemens

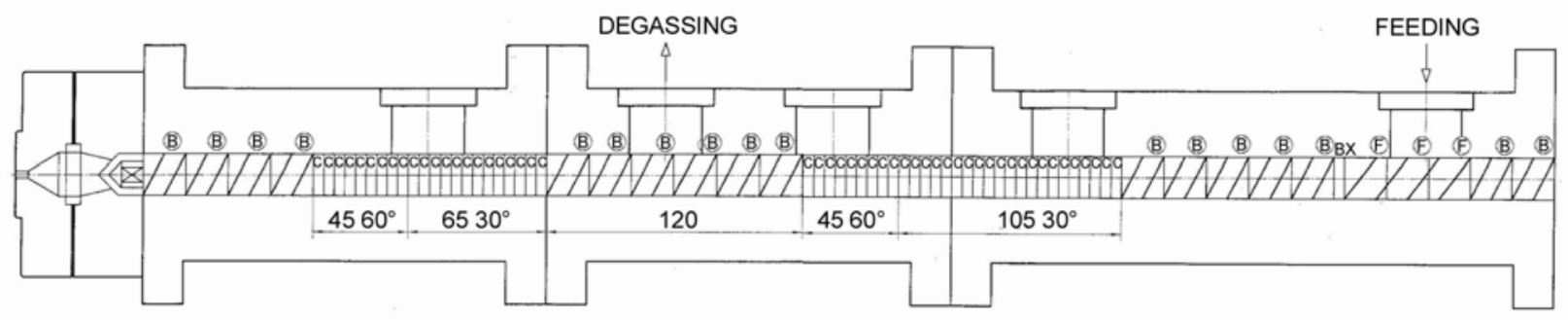

Figure 1. Screw profile of O.M.C. co-rotating intermeshing twin-screw extruder $(L / D=35, D=19 \mathrm{~mm})$ 
AG Munich, Germany) with $\mathrm{Cu} \mathrm{K}_{\alpha}$ radiation of wavelength of $0.1542 \mathrm{~nm}$. A scanning rate of $10 \mathrm{deg} / \mathrm{min}^{-1}$ was used. The distances $d_{001}$ between the silicate layers of the organoclay in the nanocomposite films were evaluated using the Bragg's equation $d_{001}=n \lambda /(2 \sin \theta)$, where $\lambda$ is the wavelength, $\theta$ is the incidence angle of the X-ray beam and $n$ is an integer.

\subsubsection{Transmission electron microscopy (TEM)}

The analyses were carried out on the radial cross section for the film samples. Ultrathin films with thickness of about $100 \mathrm{~nm}$ for TEM observation were prepared by slicing the epoxy block containing PE nanocomposite films with a Leica Ultramicrotome (Leica Microsystems, Wetzlar, Germany). The ultra-thin films of the nanocomposite films were mounted on the holey carbon films on 300 mesh copper grids and then observed by JEOL JEM-2100 (Jeol Ltd., Tkyo, Japan) under accelerated voltage of $100 \mathrm{kV}$.

\subsubsection{Rheological analysis}

The rheological characterization, including measurements of complex viscosity was performed by using a Rheometric Scientific (Piscataway Township, NJ, USA) RDA II plate-plate rotational rheometer, operating at $T=180^{\circ} \mathrm{C}$ in the frequency range comprised between $0.1-500 \mathrm{rad} / \mathrm{s}$.

\subsubsection{Fourier transform infra-red analysis (FT-IR)}

Fourier transform infra-red (FT-IR) spectra were evaluated using the Spectrum One Spectromoter by Perkin-Elmer (Weltham, MA, USA) and its Spectrum software. The spectra were obtained using 32 scans and a $4 \mathrm{~cm}^{-1}$ resolution. The powder samples were incorporated in $\mathrm{KBr}$.

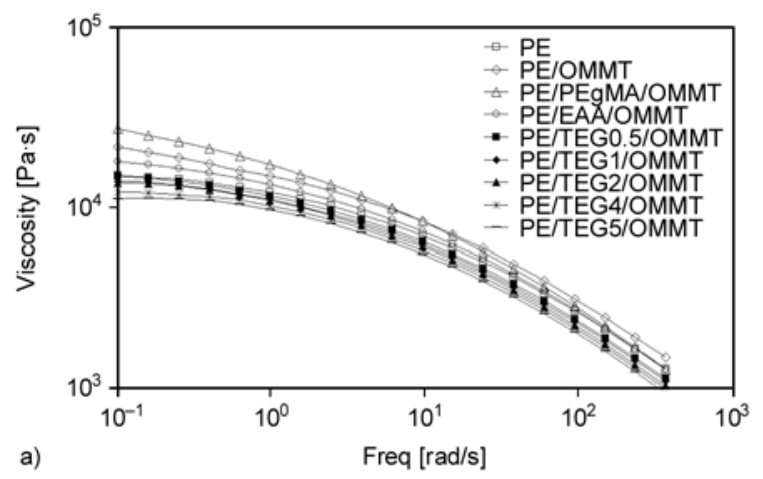

\subsubsection{Nuclear magnetic resonance analysis} (NMR)

${ }^{13} \mathrm{C}$ cross-polarization magic-angle spinning nuclear magnetic resonance $\left({ }^{13} \mathrm{C}\right.$ de-coupled $\left\{{ }^{1} \mathrm{H}\right\}$ CP-MAS NMR) spectra were obtained at room temperature on a Bruker Avance II $400 \mathrm{MHz}$ (9.4 T) spectrometer (Bruker, Ettlingen, Germany) operating at $100.63 \mathrm{MHz}$ for the ${ }^{13} \mathrm{C}$ nucleus with a MAS rate of $13 \mathrm{kHz}$ for 1024 scans, a contact time of $1.5 \mu \mathrm{s}$, and a repetition delay of $1.5 \mathrm{~ms}$.

\section{Results and discussion}

\subsection{Rheological characterization}

The viscosity measurements, in the frequencies range between $0.1-500 \mathrm{rad} / \mathrm{s}$, were carried out and the flow curves are reported in Figure 2a. In general, the OMMT presence in the polymer matrix leads to a substantial viscosity increase in the whole frequencies region. Addition of adhesion promoters, in particular of PEgMA, further increases the complex viscosity, most sizeably, at the low frequencies values. Most interestingly the TEG presence, especially at low loadings ( 0.5 and $1 \mathrm{wt} \%)$, does not modify the rheological behaviour of the composites with their viscosity being substantially equal to that of the pristine polymeric matrix. Furthermore, the TEG presence, even at high loadings (4 and $5 \mathrm{wt} \%$ ) leads to a much more pronounced decrease of the complex viscosity. The TEG additive has a very low viscosity, see 2.1 , and obviously by increasing the TEG presence, the complex viscosity of the formulated nanocomposites decreases. In Figure $2 b$ the flow curves of all investigated materials in high frequencies region are reported. The higher viscosity of PE/OMMT, in the range of $100-300 \mathrm{rad} / \mathrm{s}$ (typical shear rate range of extrusion operation) does not substantially worsen the processability of this material. The viscosity values of PE/

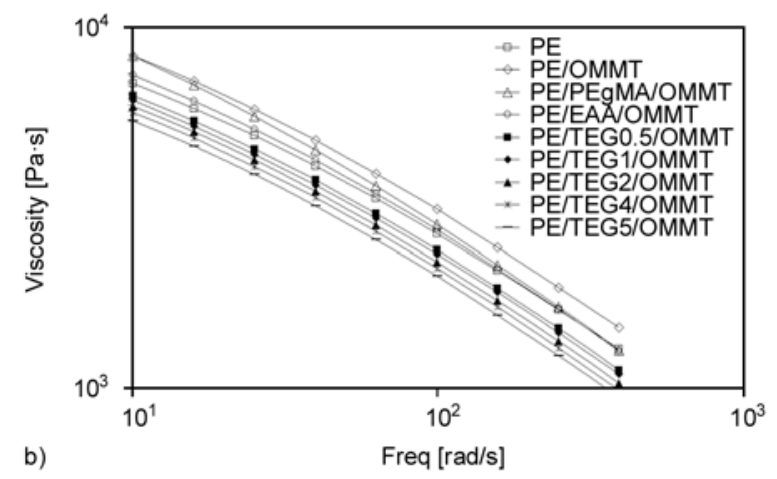

Figure 2. Complex viscosity of all the investigated materials 
gMA/OMMT and PE/EAA/OMMT nanocomposites are, at higher frequencies, close to those of the unfilled polyethylene $\mathrm{PE}$, and a comparable processability obtains. By contrast TEG, at high loadings, exerts a clear lubricating effect, while at low content, no modification of the processability was observed.

\subsection{Mechanical characterization}

In Figures 3-5, the mechanical properties, in particular, the elastic modulus, $E$, tensile strength, TS, and elongation at break, EB, are reported, in both the machine (MD) and transverse (TD) directions for polyethylene films (PE), either pristine or containing $5 \mathrm{wt} \%$ of organically modified montmorillonite (PE/OMMT), alone or together with adhesion pro- moters such as $5 \mathrm{wt} \%$ of maleic anhydride grafted polyethylene (PE/PEgMA/OMMT), of ethyleneacrylic acid copolymer (PE/EAA/OMMT) or of dispersing additives such as polar wax (PE/TEG\%/ OMMT) at different concentrations $(0.5,1,2,4$ and $5 \mathrm{wt} \%)$. The obtained results suggest that the presence of OMMT nano-particles in the composite leads to an increase of the elastic modulus with no changes, or in some systems a slight decrease, in the ultimate properties, in keeping with what already reported in the literature [5-9]. In general, in order to obtain a better dispersion of the OMMT nano-particles and achieve good performances, use of dispersing additives and/or adhesion promoters is required [10-12, 14].

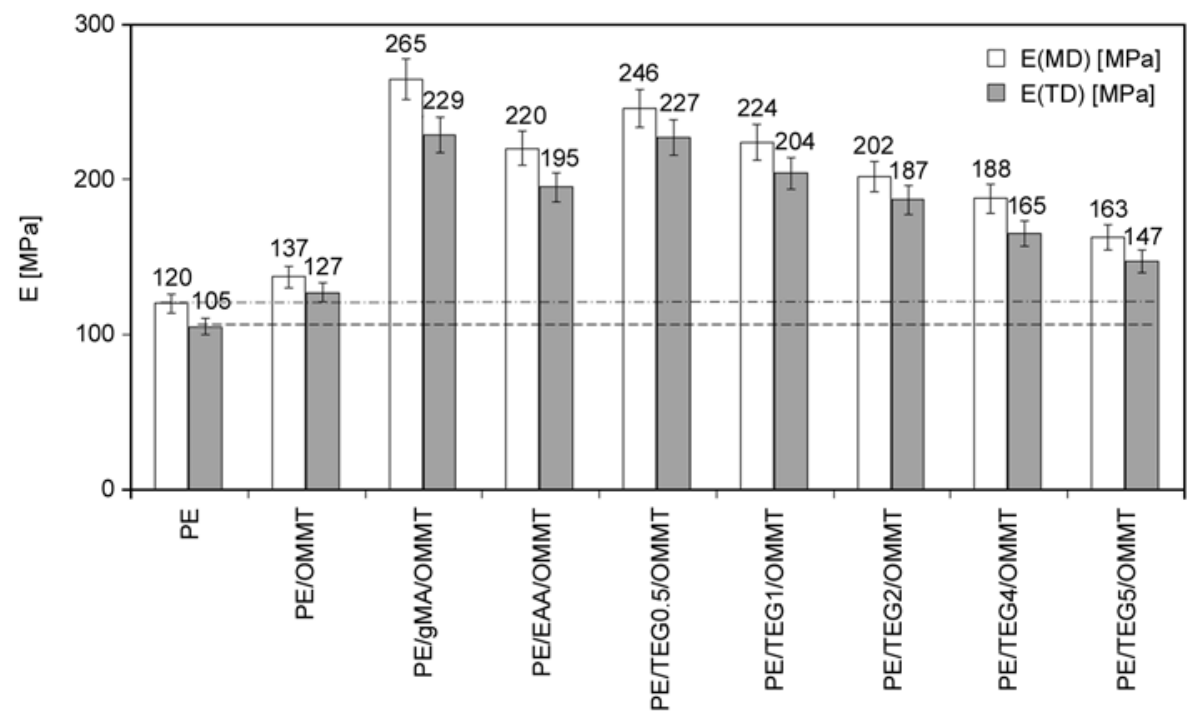

Figure 3. Elastic modulus of pristine PE film and PE/OMMT film without and with different dispersing additives in both machine (MD) and transverse (TD) directions

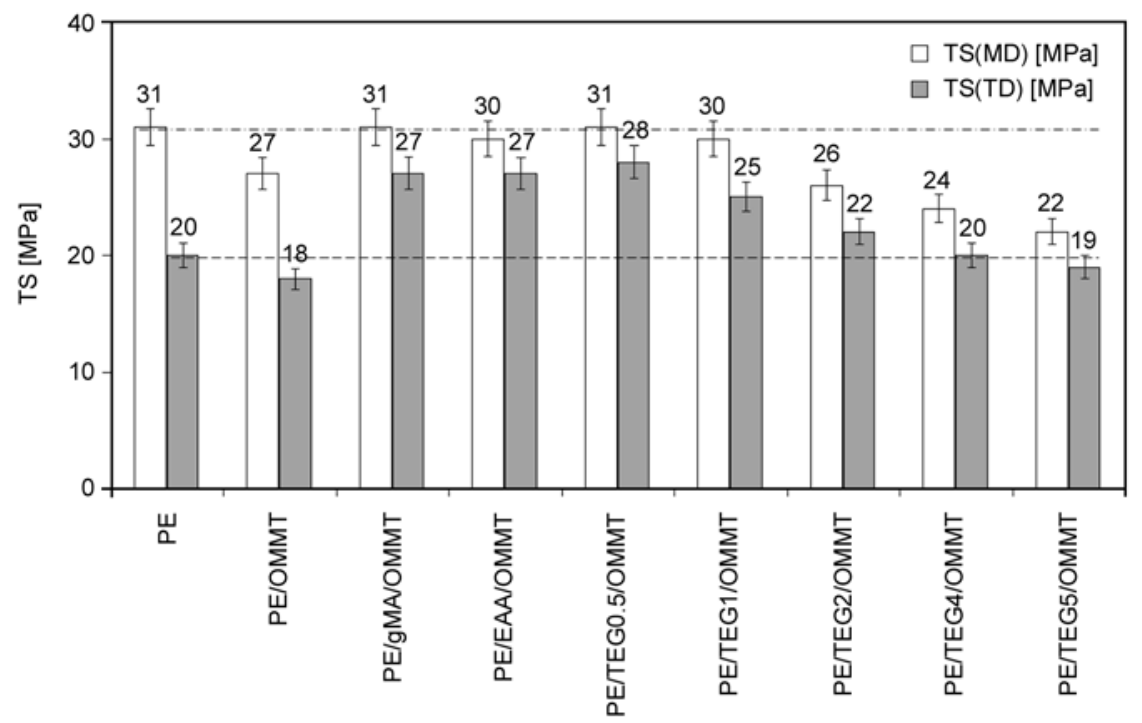

Figure 4. Tensile strength of pristine PE film and PE/OMMT film without and with different dispersing additives in both machine (MD) and transverse (TD) directions 


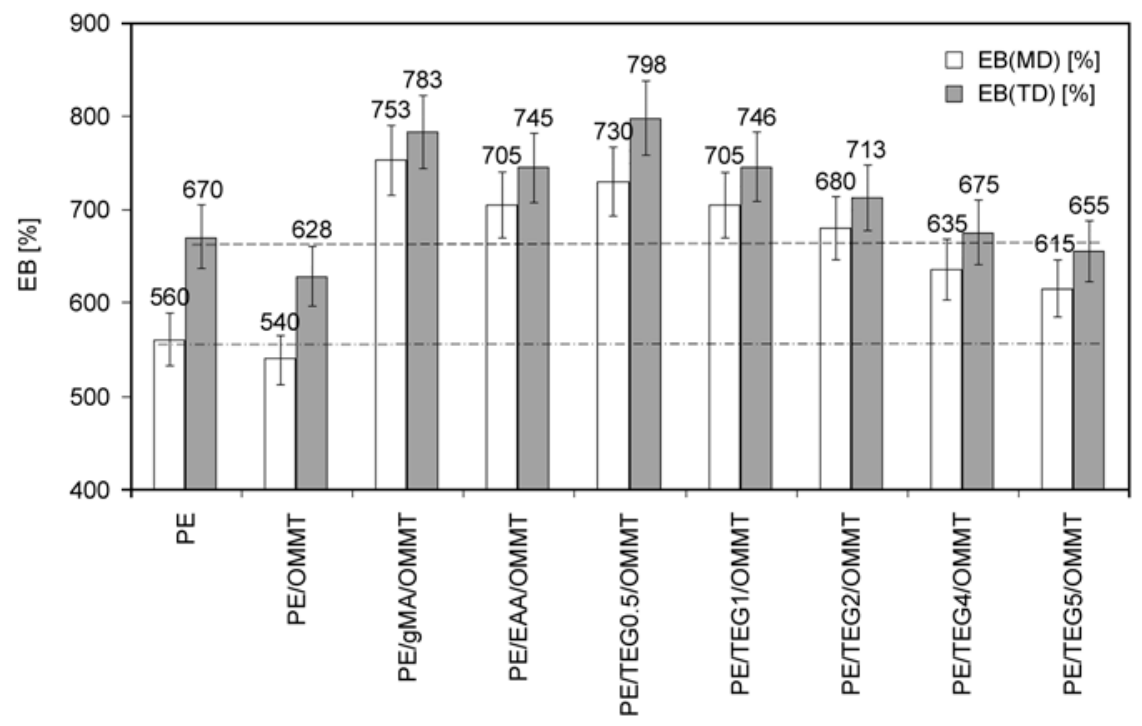

Figure 5. Elongation at break of pristine PE film and PE/OMMT film without and with different dispersing additives in both machine (MD) and transverse (TD) directions

It is interesting to note that the values of all the mechanical properties of films containing $5 \mathrm{wt} \%$ of PEgMA or $5 \mathrm{wt} \%$ of EAA are practically the same of films containing only $0.5 \mathrm{wt} \%$ of TEG. Increasing the concentration of TEG to 1 and $5 \mathrm{wt} \%$ does not produce further improvement of the films mechanical performances. It must also be noted that at high TEG loading, the films rigidity and properties at break drop. In particular, the elastic modulus of the PE/TEG5/OMMT film, in both the machine and transverse directions, decreases by about $50 \%$ with respect to the value of the PE/TEG0.5/OMMT film, even though the value is always higher than those of the pristine PE and PE/OMMT films. In parallel, a reduction of the tensile strength is observed upon a tenfold increase (i.e. to $5 \mathrm{wt} \%$ ) of the TEG concentration. On the other hand at the higher concentration of TEG (e.g. 4 and $5 \mathrm{wt} \%$ ) the elongation at break, EB, does not seem to increase.

Interestingly the inspection of the measured mechanical properties reveals that major improvements obtain at the lowest TEG loading, i.e. $0.5 \mathrm{wt} \%$, and that the mechanical behaviour of the PE/TEG0.5/ OMMT film is very similar, in both the machine and transverse directions, to that of both $\mathrm{PE} / \mathrm{PEgMA} /$ OMMT and PE/EAA/OMMT films containing higher amounts (up to one order of magnitude) of either dispersing or compatibilizing agents.

Furthermore, no benefits are obtained in the film formulation for high TEG loading (see all discussed results).
This are, indeed, interesting results and the render the use of TEG, as a new dispersing additive and/or adhesion promoter, particularly advantageous in some film formulations given the low loading values required. Further confirmation of such envisioned advantages comes also from the analysis of the observed rheological changes reported and discussed in section 3.1.

\subsection{Analysis of TEG by Fourier transform infra-red spectroscopy (FT-IR) and nuclear magnetic resonance (NMR)}

The FT-IR and NMR analysis of the TEG sample was performed and the spectra are reported in Figures 6 and 7, respectively. In the FT-IR spectra different characteristic absorption areas were identified, in particular:

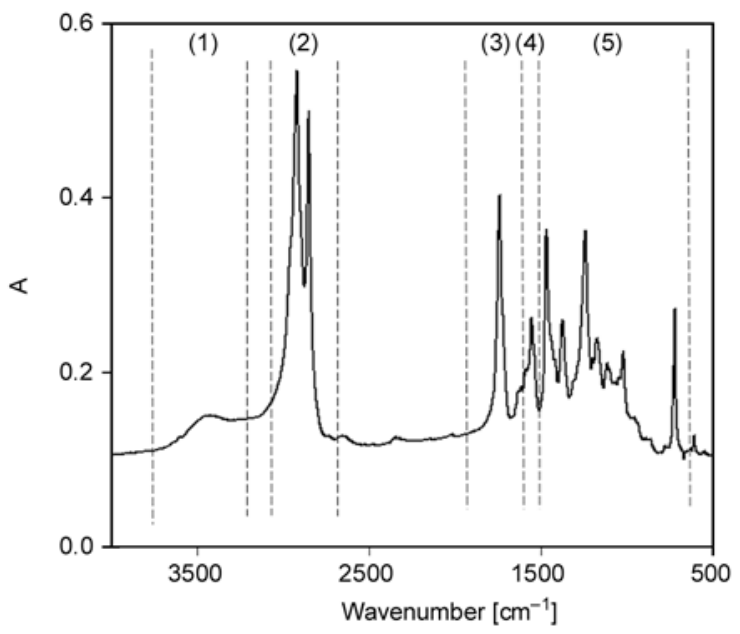

Figure 6. FT-IR spectra of TEG sample (in $\mathrm{KBr}$ ) 


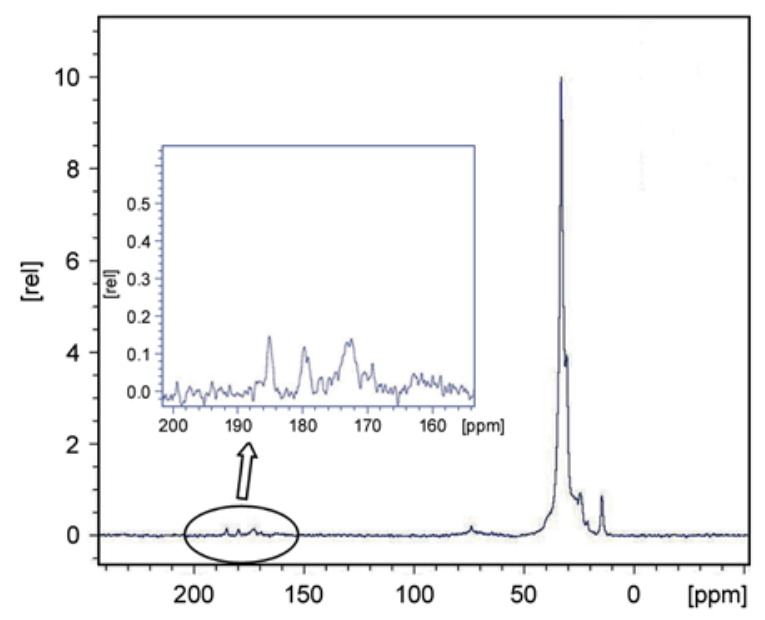

Figure 7. NMR analysis

Area 1: hydroxyl group region (3200-3700 $\left.\mathrm{cm}^{-1}\right)$. The broad peaks in the spectra suggest the presence of hydroxyl bonds.

Area 2: C-H stretching in the alkanes (3000$2800 \mathrm{~cm}^{-1}$ ). The TEG spectra shows well distinct absorption peaks at about $2918 \mathrm{~cm}^{-1}$ and about $2844 \mathrm{~cm}^{-1}$ due to the asymmetrical and symmetrical stretching vibration of the methylene groups, respectively.

Area 3: carbonyl region $\left(1900-1600 \mathrm{~cm}^{-1}\right)$. The TEG spectra shows well distinct peak at $1738 \mathrm{~cm}-1$ due to the presence of COX functional groups.

Area $4\left(1640-1500 \mathrm{~cm}^{-1}\right)$ : The TEG spectra reveals the presence of well a distinct peak at $1553 \mathrm{~cm}^{-1}$ due to the presence of secondary acyclic amides $(-\mathrm{CONH})$; the absorption involves the coupling of the $\mathrm{N}-\mathrm{H}$ bending and $\mathrm{C}-\mathrm{N}$ stretching vibrations.

Area $5\left(<1500 \mathrm{~cm}^{-1}\right)$ : The spectra show absorption peaks at about 1466 and $1370 \mathrm{~cm}^{-1}$ due to the inplane bending and symmetric bending vibrations of methyl groups. Moreaover, a well distinct peak at $719 \mathrm{~cm}^{-1}$ is visible, due to the in-plane bending of the methylene groups.

The NMR analysis confirms the above FT-IR analysis. In particular, the well distinct peaks in the spectra at $<50 \mathrm{ppm}$ can be attributed to the presence of numerous $-\mathrm{CH}_{2}-$ and $-\mathrm{CH}_{3}$ groups. The small peak between 50 and $100 \mathrm{ppm}$ is due to the carbon atoms carrying hydroxyl groups. Furthermore, the small peaks between 150 and 200 ppm reveal the presence of amide and carboxyl groups.

The large amounts of methylene groups, confirmed by both analyses, suggest that TEG is a low molecular weight sample, according to the rheological data (see experimental part, i.e. description of the used materials).

The accurate FT-IR and NMR analyses suggest the presence of amides and carboxyl functionalities on the low molecular aliphatic chains in TEG polar wax structure.

\subsection{Morphological analysis}

\subsubsection{X-ray analysis}

In Figure 8, the X-ray traces of pristine OMMT, pristine TEG, PE/OMMT and PE/additive/OMMT, with of different dispersing additives are plotted, and Table 2 reports the interlayer distances of the investigated films, calculated using the Bragg's formula. All the OMMT-films show increased interlayer distance (main diffraction peak), with respect to the interlayer distance obtained for the pristine OMMT film. The latter film shows a secondary diffraction peak between 6 and 8 degrees, that is much smaller in the PE/OMMT system. The main peaks of PE/PEgMA/OMMT and PE/EAA/OMMT films are shifted to the left and the calculated interlayer distances are 3.56 and $3.37 \mathrm{~nm}$, respectively. The presence of both compatibilizers leads to a decrease of the main peak intensity, see Figure 8a, that is more pronounced than that observed for the weakly intercalated PE/OMMT sample. As well known, the absence of the diffraction peak in X-ray trace suggests the presence of exfoliated clay morphology.

It is very interesting to highlight that the presence of TEG leads to an increase of the interlayer distance than the PE/OMMT sample but at high loadings, i.e. 1 and $5 \mathrm{wt} \%$, the diffraction intensities significantly increase and the peaks are very intense, see Figure 8b. Furthermore, the sample PE/T0.5/ OMMT shows lower diffraction intensity than the $\mathrm{PE} / \mathrm{OMMT}$ one and this diffraction trace is similar

Table 2. Main peaks and calculated interlayer distance, using the Bragg's formula, of the investigated nanocomposite films

\begin{tabular}{|l|c|c|}
\hline \multicolumn{1}{|c|}{ Sample } & Main peak, $\mathbf{2 \theta}$ & $\mathbf{d}_{\mathbf{0 0 1}}[\mathbf{n m}]$ \\
\hline Cloisite $^{\circledR}$ 15A & 2.80 & 3.15 \\
\hline PE/OMMT & 2.67 & 3.30 \\
\hline PE/PEgMA/OMMT & 2.48 & 3.56 \\
\hline PE/EAA/OMMT & 2.62 & 3.37 \\
\hline PE/TEG0.5/OMMT & 2.58 & 3.42 \\
\hline PE/TEG1/OMMT & 2.50 & 3.53 \\
\hline PE/TEG4/OMMT & 2.42 & 3.65 \\
\hline PE/TEG5/OMMT & 2.35 & 3.76 \\
\hline Tegomer ${ }^{(B)}$ E525 & 1.85 & 4.77 \\
\hline
\end{tabular}


to the trace obtained for the samples compatibilized with PEgMA and PEgAA.
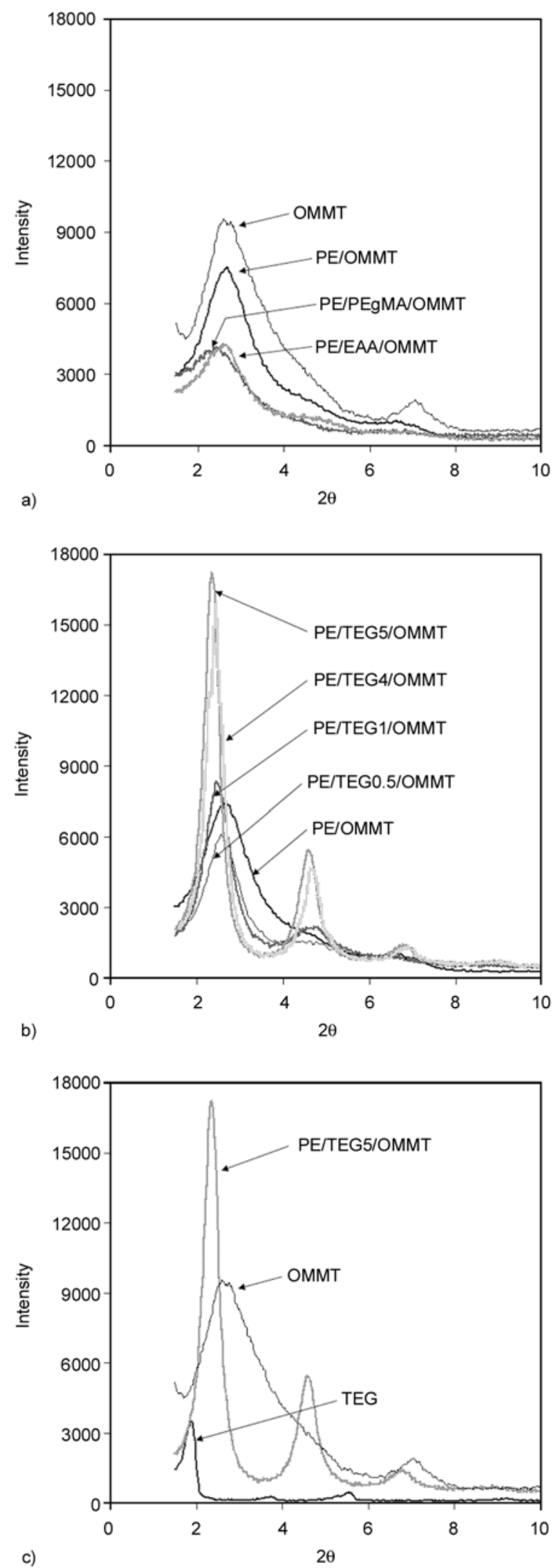

Figure 8. X-ray diffraction trace of all the investigated samples
In order to better understand the effect of the amphiphilic block co-polymer presence on the increase of the diffraction intensity, the X-ray analysis on the pristine TEG was performed. In Figure $8 \mathrm{c}$, the X-ray trace of the pristine TEG, pristine OMMT and PE/TEG5/OMMT samples were shown. It is evident that the clay morphology modification occurs because of the polar wax (i.e. TEG) presence, given the very intense peaks and the increase in the intensity for PE/TEG5/OMMT sample. It seems that the small polar wax chains (having very low viscosity values, as reported in the experimental part), by strong interaction with the organic modifier, are able to penetrate the clay layers (the interlayer distance increase), but are not able to separate the layers into the clay tactoids, see Figure 9. Considering the strongly polar nature of the amphiphilic block co-polymer chains, it also could be hypothesized that the presence of wax chaina in the clay galleries inhibits the penetration of the polyethylene chains into the tactoid galleries; a similar hypothesis was made by Luyt and Geethamma [25]. In order to better explain the hypothesis of the easier intercalation into the clay galleries, but no exfoliation ability, of the TEG amphiphilic block co-polymer molecules than the PEgMA or EAA long polymeric chains, in Figure 9, the possible formation clay morphology in the nanocomposites is shown. Really, the penetration of PEgMA, partially EAA

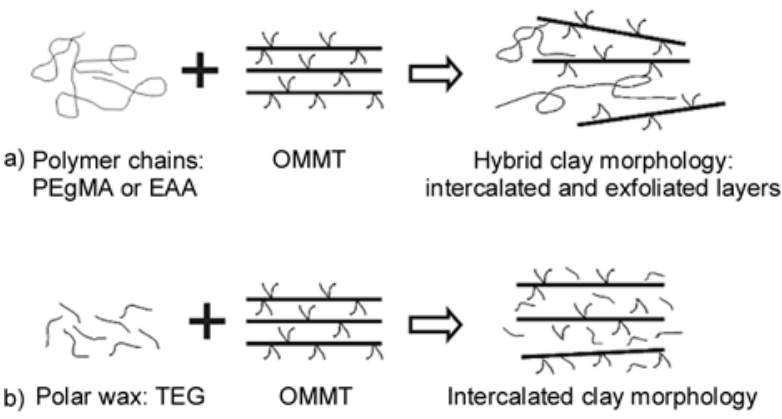

Figure 9. Clay morphology of PE/OMMT with different dispersing additives: (a) Formation of hybrid clay morphology, i.e. the PEgMA or EAA polymer chains are able to intercalate and in some cases to exfoliate the clay layers. The intercalation ability only of matrix chains, i.e. PE polymer chains, is very reduced, as well know. (b) Formation of preferentially intercalated morphology due to the reduced ability of the TEG molecules to separate the clay layers. The TEG molecules are high penetration ability considering their polar nature but reduced ability in layer separation due to their small dimension. 
chains and PE macromolecules, during melt processing explains the intercalation effect and considering the specific intrinsic properties and nature explain also the exfoliation effect, i.e. that the long polymer chains are able to delaminate the tactoids. While the TEG molecules, having polar nature and small dimension are able to intercalate the clay tactoids during melt processing, in particular at high TEG loading, and the penetration of the PE chains into clay galleries are not favoured.

Furthermore, the physically-absorbed organic modifier on the clay particles surface it is likely to promote, especially at high TEG loading (e.g. 4 and $5 \% \mathrm{wt}$.), the cluster formation of clay particles (see 3.4.2), by interaction among the wax polar groups, and, this would further inhibit the otherwise beneficial penetration of the polyethylene chains into the clay platelets that would improve the mechanical properties of the films.

\subsubsection{Transmission electron microscopy analysis (TEM)}

The TEM analysis of PE/OMMT (a), PE/PEgMA/ OMMT (b), PE/TEG0.5/OMMT (c) and PE/TEG5/ OMMT (d) films was carried out and the micrographs are reported in Figure 10. The PE/OMMT sample shows the presence in the system of clay clusters with dimensions larger than $200 \mathrm{~nm}$. The isolated platelets are not visible, suggesting that the clay morphology is predominantly intercalated, in accord with the X-ray analysis results. The PE/ PEgMA/OMMT sample shows clay tactoids with much smaller dimensions, and also a large number of isolated clay platelets are clearly visible, see Figure $10 \mathrm{~b}$. The presence of some tactoids leads to appearance of the diffraction peaks in the X-ray trace and the clay morphology is hybrid with a large number of exfoliated platelets.

The discussion about the clay morphology in the samples additivated with TEG, appears to be more complex. In fact, the micrographs of both investigated samples, i.e. PE/TEG0.5/OMMT (c) and PE/ TEG5/OMMT (d) respectively, show the presence of large clay clusters, whose dimensions become larger at high TEG loading. These observations are in agreement with the X-ray analysis, in particular, the chains of the polar wax are arranged between the platelets of the clay and, due to their polar nature, significant particle re-aggregation occurs; this effect is, as noted above, more pronounced at highest TEG loading. Furthermore, it is reasonable to expect that the at high(er) TEG loadings some polar wax chains are also present on the external surface of the tactoids and this would promote, by polar-polar groups interaction, the clay particles re-aggregation.

In fact, the PEgMA presence leads to a formation of a large number exfoliated platelets and consequently the rigidity of the system increases without ductility loss. Moreover, the TEG presence leads to the formation of predominantly intercalated clay structures but at high loadings leads to some reaggregation of the intercalated clay tactoids, most likely by association between the polar groups of TEG. It would then seem that this new morphology could be responsible for the observed worsening in the mechanical behaviour with respect to the PEgMA and EAA compatibilized samples; especially, at high TEG loading. At low TEG loading, i.e. $0.5 \mathrm{wt} \%$, the polar wax chains are mainly intercalated into the tactoids and the re-aggregation particle process is not significantly pronounced.

\subsubsection{Scanning electron microscopy analysis (SEM)}

In order to evaluate the system morphology variations at microscopic level, the SEM micrographs at two different magnifications of the investigated films are reported in Figure 11. The morphology of PE/OMMT sample, not containing compatibilizer or dispersing additives is not uniform and also a poor adhesion between the clay particles and the matrix is observed. Furthermore, on the liquid nitrogen fractured surface of the PE/OMMT film are clearly noticeable some clay particles/cluster having micrometric dimensions. Addition of PEgMA at the $5 \mathrm{wt} \%$, significantly improves the film morphology. The beneficial effect imparted by low loading of TEG, i.e. $0.5 \mathrm{wt} \%$, is clearly evident from the inspection of the reported SEM micrographs. The fractured surface of this film is uniform and no reaggregated clay clusters are observed. Interestingly, by increasing the TEG loadings, i.e. 1, 4 and $5 \mathrm{wt} \%$, the above reported morphology improvement is no longer observed as seen in the reported micrographs, and these remarks are in full agreement with the observed differences in mechanical behaviour and other morphological analyses. 


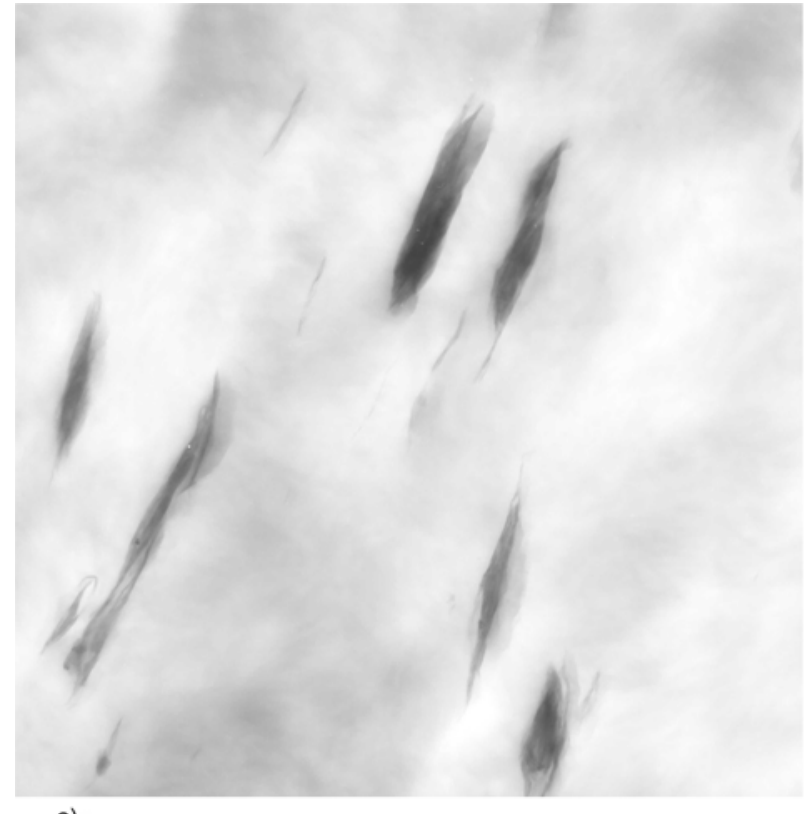

a)

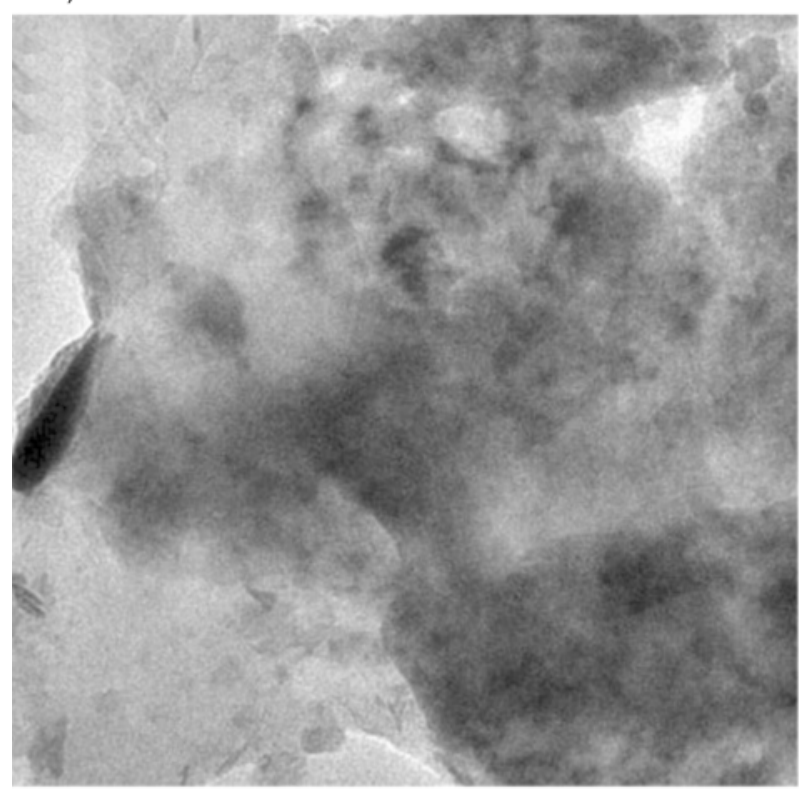

c)

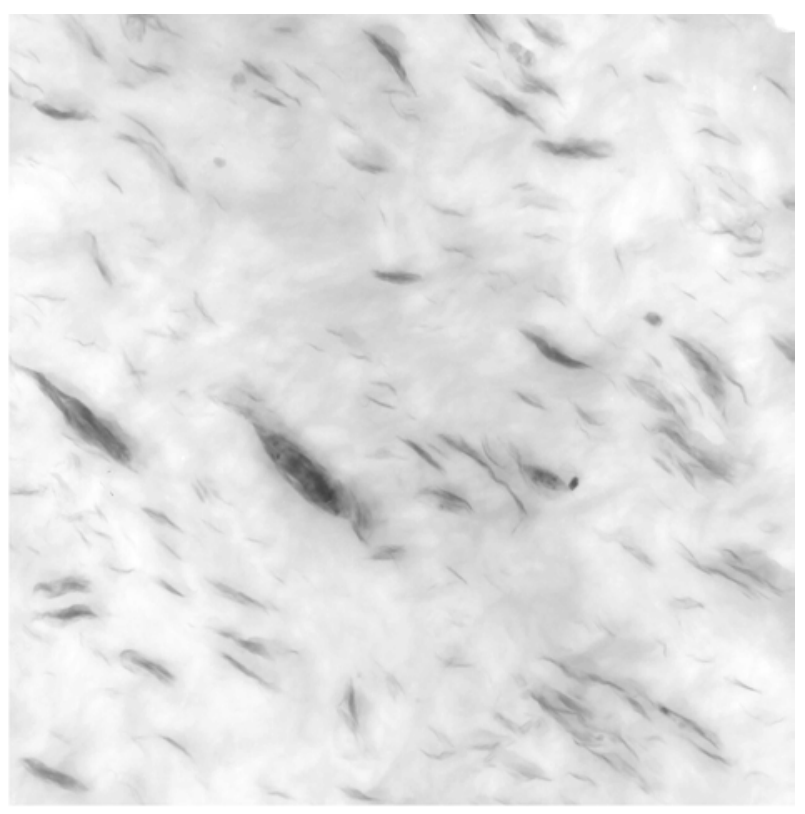

b)

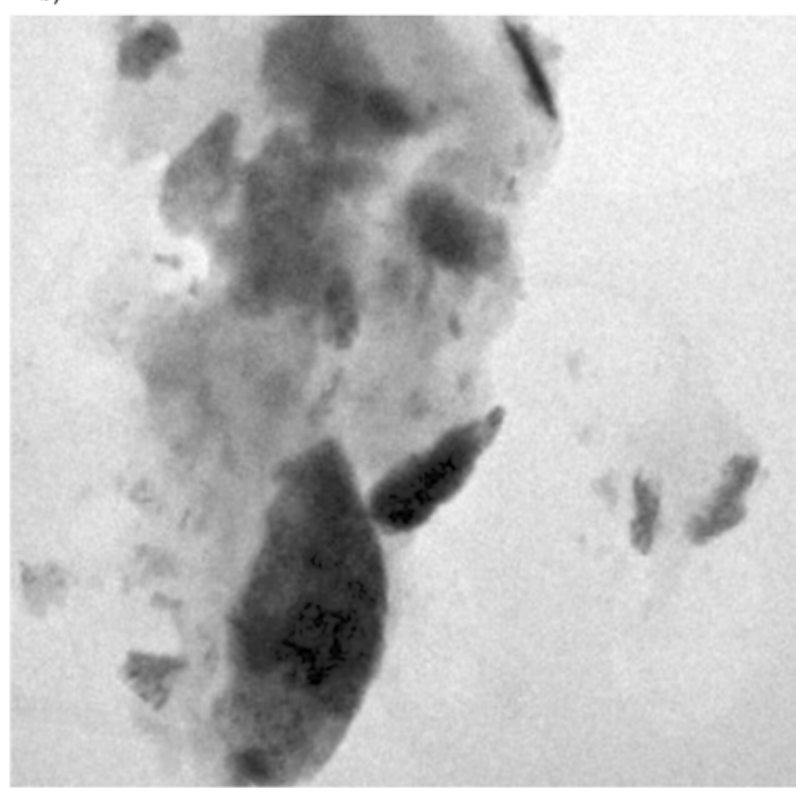

d)

Figure 10. TEM micrographs of the investigated PE/OMMT (a), PE/PEgMA/OMMT (b), PE/TEG0.5/OMMT (c) and PE/TEG5/OMMT (d) films

\section{Conclusions}

In this work, a polar wax was used as dispersing additive in PE/OMMT film preparation with the aim of modifying, and possibly improving, the dispersion of an organically modified nanoclay (OMMT) in a PE matrix at relatively low loading levels. The obtained results suggest that the macroscopic properties of the films observed when the polar wax (TEG) was added at low concentration, i.e. $0.5 \mathrm{wt} \%$, are similar to those obtained by adding PEgMA and EAA compatibilizers at $5 \mathrm{wt} \%$. Furthermore, by increasing the TEG loading, i.e. 1-

$5 \mathrm{wt} \%$, no improvement of the macroscopic performance was observed. At the higher loading levels the low molecular weight and polar nature of TEG chains promote its arrangement into the galleries of the organically modified clay and this somewhat hinders the polymer chains intercalation between the clay layers, with no improvement of the PE film mechanical and thermal properties. The obtained results suggest that the amphiphilic dispersing agent, at low loading levels, may advantageously be used as an alternative to PEgMA and EAA compatibilizers in the formulation of nanocomposite poly- 


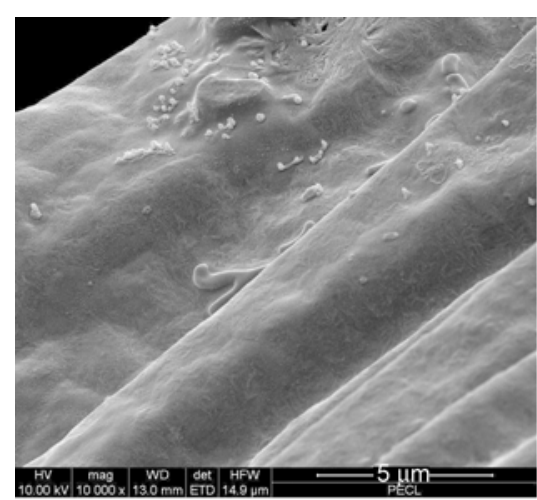

a)

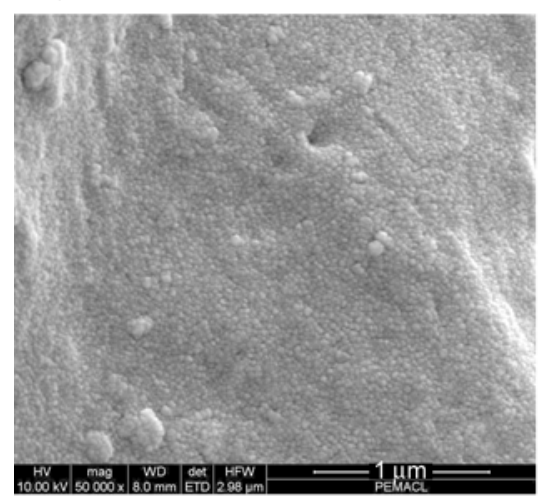

d)

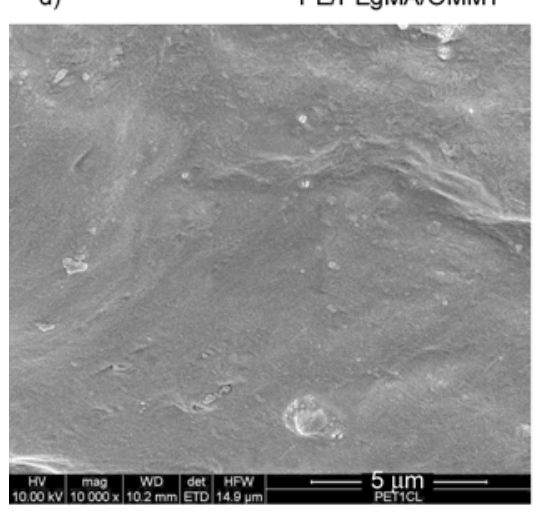

g)

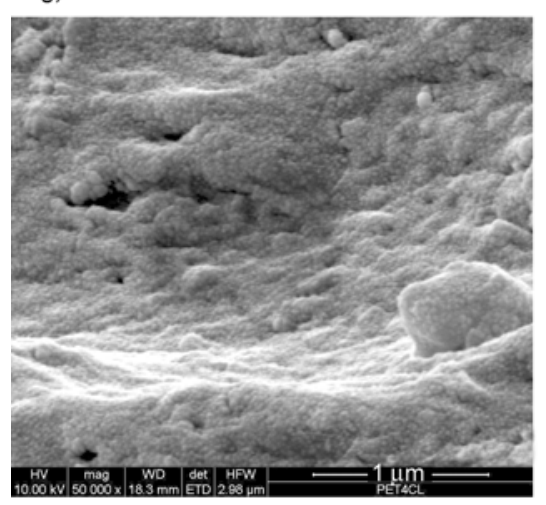

j)

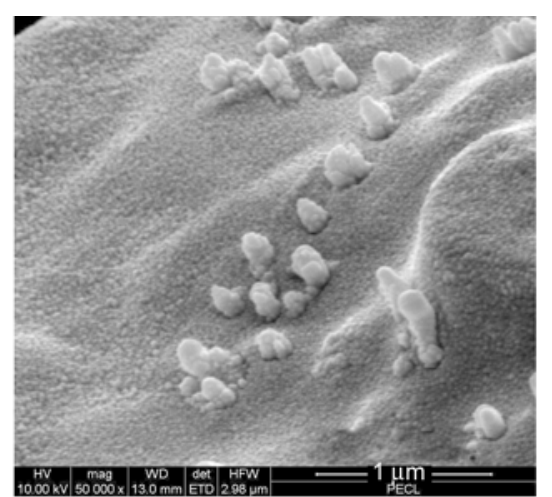

b)

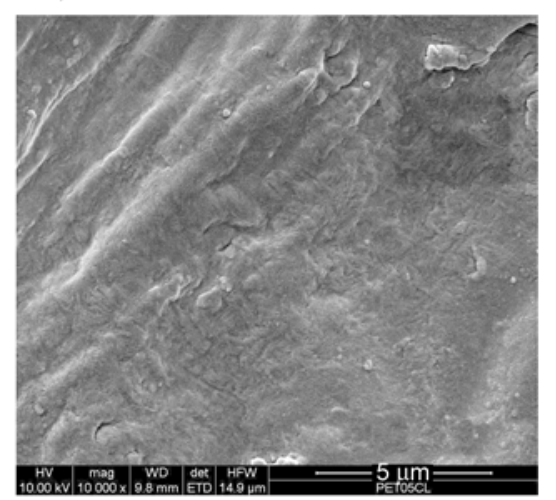

e)

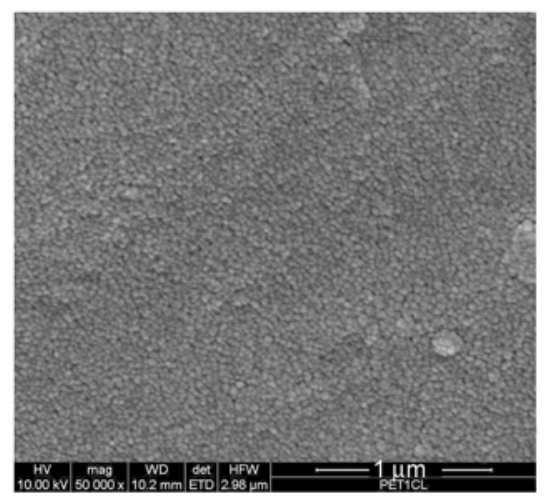

h)

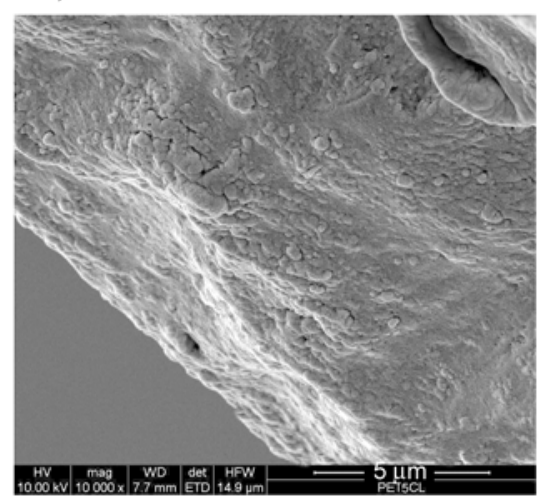

k)

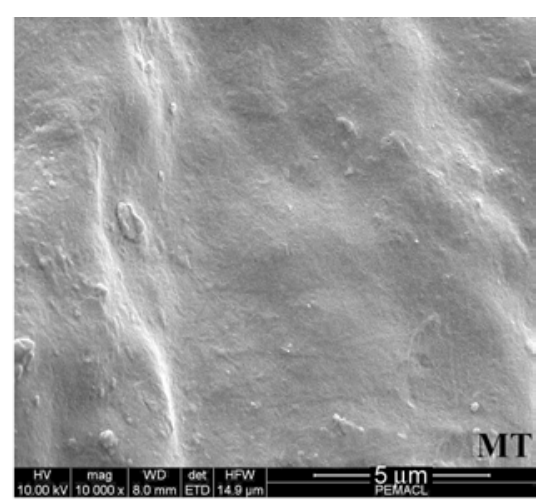

c)

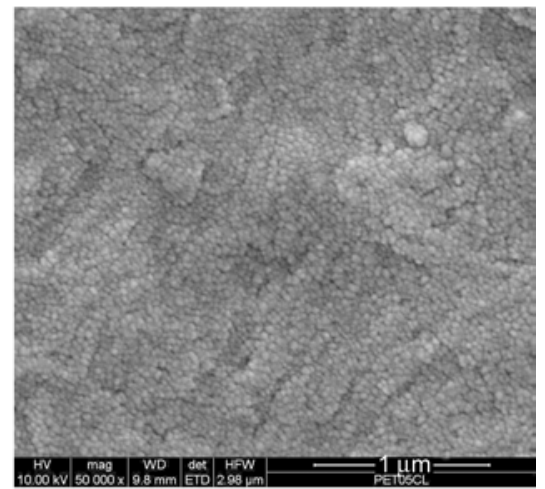

f)

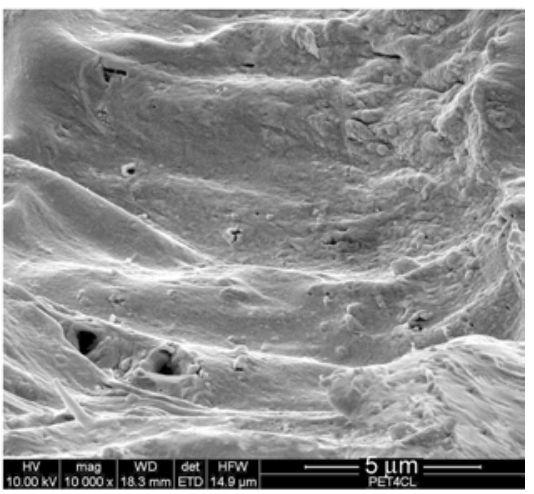

i)

PE/TEG4/OMMT

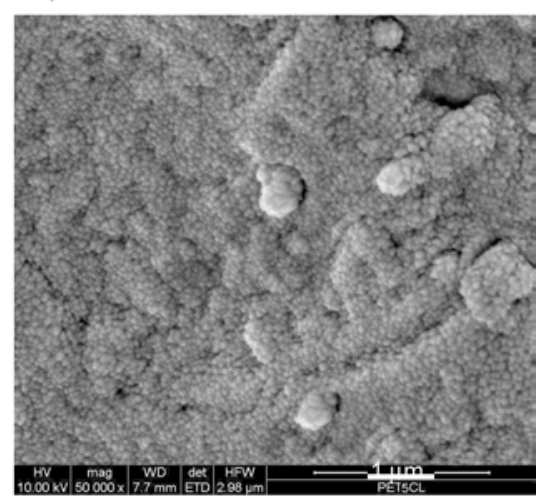

PE/TEG5/OMMT

Figure 11. SEM micrographs at two different magnifications $(10000 \times$ and $50000 \times)$ of the investigated films

olefin films, and its use would allow obtaining similar macroscopic performance improvement at substantially lower loading levels.

\section{Acknowledgements}

V.M. thanks Evonik Goldschmidt Italia s.r.l for kindly providing sample of Tegomer ${ }^{\circledR}$ E 525 polar wax. 


\section{References}

[1] Alexandre M., Dubois P.: Polymer-layered silicate nanocomposites: Preparation, properties and uses of a new class of materials. Materials Science and Engineering R: Reports, 28, 1-63 (2000).

DOI: $10.1016 / \mathrm{S} 0927-796 X(00) 00012-7$

[2] Pinnavaia T. J., Beall G. W.: Polymer-clay nanocomposites. Wiley, Chichester (2000).

[3] Ren J., Silva A. S., Krishnamoorti R.: Linear viscoelasticity of disordered polystyrene-polyisoprene block copolymer based layered-silicate nanocomposites. Macromolecules, 33, 3739-3746 (2000).

DOI: $10.1021 / \mathrm{ma992091 \textrm {u }}$

[4] Dennis H. R., Hunter D. L., Chang D., Kim S., White J. L., Cho J. W., Paul D. R.: Effect of melt processing conditions on the extent of exfoliation in organoclaybased nanocomposites. Polymer, 42, 9513-9522 (2001). DOI: 10.1016/S0032-3861(01)00473-6

[5] Krishnamoorti R., Ren J., Silva A. S.: Shear response of layered silicate nanocomposites. Journal of Chemical Physics, 114, 4968-4973 (2001).

DOI: $10.1063 / 1.1345908$

[6] Ray S. S., Okamoto M.: Polymer/layered silicate nanocomposites: A review from preparation to processing. Progress in Polymer Science, 28, 1539-1641 (2003).

DOI: $10.1016 /$ j.progpolymsci.2003.08.002

[7] Hotta S., Paul D. R.: Nanocomposites formed from linear low density polyethylene and organoclays. Polymer, 45, 7639-7654 (2004).

DOI: 10.1016/j.polymer.2004.08.059

[8] Zeng Q. H., Yu A. B., Lu G. Q., Paul D. R.: Clay-based polymer nanocomposites: Research and commercial development. Journal of Nanoscience and Nanotechnology, 5, 1574-1592 (2005).

DOI: $10.1166 /$ jnn.2005.411

[8] La Mantia F. P., Dintcheva N. T., Filippone G., Acierno D.: Structure and dynamics of polyethylene/ clay films. Journal of Applied Polymer Science, 102, 4749-4758 (2006).

DOI: 10.1002/app.25009

[9] Zhang M., Sundararaj U.: Thermal, rheological, and mechanical behaviors of LLDPE/PEMA/clay nanocomposites: Effect of interaction between polymer, compatibilizer, and nanofiller. Macromolecular Materials and Engineering, 291, 697-706 (2006).

DOI: 10.1002/mame.200500399

[10] Durmus A., Kasgoz A., Macosko C. W.: Linear low density polyethylene (LLDPE)/clay nanocomposites. Part I: Structural characterization and quantifying clay dispersion by melt rheology. Polymer, 48, 4492-4502 (2007). DOI: 10.1016/j.polymer.2007.05.074
[11] Sánchez-Valdes S., López-Quintanilla M. L., Ramírez Vargas E., Medellín-Rodríguez F. J., Gutierrez-Rodriguez J. M.: Effect of ionomeric compatibilizer on clay dispersion in polyethylene/clay nanocomposites. Macromolecular Materials and Engineering, 291, 128-136 (2006). DOI: $10.1002 /$ mame. 200500330

[12] Shah R. K., Hunter D. L., Paul D. R.: Nanocomposites from poly(ethylene-co-methacrylic acid) ionomers: Effect of surfactant structure on morphology and properties. Polymer, 46, 2646-2662 (2005).

DOI: $10.1016 /$ j.polymer.2005.01.062

[13] Filippi S., Marazzato C., Magagnini P., Minkova L., Dintcheva N. T., La Mantia F. P.: Organoclay nanocomposites from ethylene-acrylic acid copolymers. Macromolecular Materials and Engineering, 291, 1208-1225 (2006).

DOI: $10.1002 /$ mame.200600217

[14] Filippi S., Dintcheva N. T., Scaffaro R., La Mantia F. P., Polacco G., Magagnini P.: Effects of organoclay on morphology and properties of nanocomposites based on LDPE/PA-6 blends without and with SEBS-g-MA compatibilizer. Polymer Engineering and Science, 49, 1187-1197 (2009). DOI: $10.1002 /$ pen.21361

[15] Xu Y., Fang Z., Tong L.: On promoting intercalation and exfoliation of bentonite in high-density polyethylene by grafting acrylic acid. Journal of Applied Polymer Science, 96, 2429-2434 (2005).

DOI: 10.1002/app. 21708

[16] Pavliková S., Thomann R., Reichert P., Mülhaupt R., Marcinčin A., Borsig E.: Fiber spinning from poly (propylene)-organoclay nanocomposite. Journal of Applied Polymer Science, 89, 604-611 (2003). DOI: $10.1002 / a p p .11870$

[17] Zhai H., Xu W., Guo H., Zhou Z., Shen S., Song Q.: Preparation and characterization of PE and PE-g$\mathrm{MAH} /$ montmorillonite nanocomposites. European Polymer Journal, 40, 2539-2545 (2004).

DOI: $10.1016 /$ j.eurpolymj.2004.07.009

[18] Wang Y., Chen F-B., Li Y-C., Wu K-C.: Melt processing of polypropylene/clay nanocomposites modified with maleated polypropylene compatibilizers. Composites Part B: Engineering, 35, 111-124 (2004). DOI: $10.1016 / \mathrm{S} 1359-8368(03) 00049-0$

[19] Liang G., Xu J., Bao S., Xu W.: Polyethylene/maleic anhydride grafted polyethylene/organic-montmorillonite nanocomposites. I. Preparation, microstructure, and mechanical properties. Journal of Applied Polymer Science, 91, 3974-3980 (2004).

DOI: $10.1002 / a p p .13612$ 
[20] Mlynarčíková Z., Kaempfer D., Thomann R., Mülhaupt R., Borsig E., Marcinčin A.: Syndiotactic poly (propylene)/organoclay nanocomposite fibers: Influence of the nano-filler and the compatibilizer on the fiber properties. Polymers for Advanced Technologies, 16, 362-369 (2005).

DOI: $10.1002 /$ pat.602

[21] Chow W. S., Abu Bakar A., Mohd Ishak Z. A., KargerKocsis J., Ishiaku U. S.: Effect of maleic anhydridegrafted ethylene-propylene rubber on the mechanical, rheological and morphological properties of organoclay reinforced polyamide 6/polypropylene nanocomposites. European Polymer Journal, 41, 687-696 (2005). DOI: 10.1016/j.eurpolymj.2004.10.041

[22] Lee J-H., Jung D., Hong C-E., Rhee K. Y., Advani S. G.: Properties of polyethylene-layered silicate nanocomposites prepared by melt intercalation with a PP-g-MA compatibilizer. Composites Science and Technology, 65, 1996-2002 (2005).

DOI: $10.1016 /$ j.compscitech.2005.03.015
[23] Dintcheva N. T., Marino R., La Mantia F. P.: The role of the matrix-filler affinity on morphology and properties of polyethylene/clay and polyethylene/compatibilizer/clay nanocomposites drawn fibers. e-Polymers, no. 054 (2009).

[24] Durmuş A., Woo M., Kasgöz A., Macosko C. W., Tsapatsis M.: Intercalated linear low density polyethylene (LLDPE)/clay nanocomposites prepared with oxidized polyethylene as a new type compatibilizer: Structural, mechanical and barrier properties. European Polymer Journal, 43, 3737-3749 (2007).

DOI: $10.1016 /$ j.eurpolymj.2007.06.019

[25] Luyt A. S., Geethamma V. G.: Effect of oxidized paraffin wax on the thermal and mechanical properties of linear low-density polyethylene-layered silicate nanocomposites. Polymer Testing, 26, 461-470 (2007). DOI: $10.1016 /$ j.polymertesting.2006.12.015 